\title{
FACTORS AFFECTING THE EFFECTIVENESS OF EMPLOYEES' PERFORMANCE APPRAISAL IN PRIVATE HOSPITALS IN MALAYSIA
}

\author{
Mandy Kim-Man Mok* \\ University of Reading Malaysia \\ Yeen-Yie Leong \\ Nilai University
}

\begin{abstract}
Many organizations conduct performance appraisal to evaluate their employees' productivity and performance. Effective performance appraisal leads to accurate reviews and thereafter some compensation for the employees who have performed and contributed to their organizations. An effective performance appraisal process is necessary to ensure accurate performance appraisal outcomes. In year 2016, the number of private hospitals in Malaysia is recorded higher than the public hospitals where 216 as compared to 153 (Ministry of Health Malaysia, 2013). Seeing that the healthcare standards demand is high in the private sectors, it is crucial to align employees' standard of performance with the organizational standards, especially through effective performance appraisal which able to keep track of employees' performance standard. This study examines the factors affect the effectiveness of employees' performance appraisal in private hospitals in Malaysia. The factors are performance appraisal process which included planning, controlling and decision making, level of trust, perceived fairness and level of communication. Research questionnaires were distributed to selected private hospitals' employees to get the relevant data. Data collected were further analyzed using Statistical Package for the Social Science (SPSS) software to find out the results. The results show that only two factors which are performance appraisal process and perceived fairness have significant effect on effectiveness of performance appraisal. The results of the study can be implied by the human resource managers to improve on the significant factors that can affect the performance appraisal system.
\end{abstract}

Keywords: Performance Appraisal, Trust, Perceived Fairness, Communication, Employees.

Received: 16 April 2019

Accepted: 30 December 2020

https://doi.org/10.33736/ijbs.3174.2021

\section{INTRODUCTION}

In today's world, employees are no longer loyal followers who just receive commands from the top, but also as an individual who hunger for feedback and recognition for their long-term contributions towards the organization. Performance appraisal is important which is unavoidable and universal especially in an organization, where people tend to judge the work performance of

\footnotetext{
* Corresponding author: University of Reading Malaysia, Henley Business School Malaysia, Persiaran Graduan, Kota Ilmu, Educity, 79200 Iskandar Puteri, Johor; Tel: +60(7)-2686356; Fax: +60(7)-2686202; Email: k.mok@ reading.ac.uk
} 
others (Cappelli \& Conyon, 2018). Thus, forming a structured system of appraisal is essential in order to avoid any wrong judgment. Performance appraisal is defined as a formal evaluation and rating of employees by their superiors followed by a review meeting (Armstrong, 2009; Iqbal, Akbar, Budwar \& Ali, 2019). It is a medium where several parties are involved in understanding and evaluating output of performance within an informed standards and competency requirements. In each business organization, especially in service industry, intellectual property is the main asset to run functional activities in the organization. This means that the performance of the employees poses as an important compound in achieving organizational goals. Hence, performance appraisal becomes a critical tool in motivating employees to be more productive and to ensure that the employees' outputs are aligned with the organizational objectives (Gichuhi, Abaja \& Ochieng, 2013). A critical evaluation on the outcome of performance appraisal may disclose the need for rewards, training, development and counseling among employees.

Moreover, many organizations still rely on the subjective evaluation from the outcome of performance appraisal to make several important decisions. However, due to the subjectivity of the performance appraisal, many researches had done studies about the errors, bias, lack of accuracy and unfairness of most performance appraisals. Important decisions that rely on performance appraisal remain questionable, which included decision on merit pay or compensation system, where employees who get higher merit rate will get higher rewards in terms of salary pay (DeNisi \& Murphy, 2017).

In each business organization, especially in-service industry, intellectual property is the main asset to run functional activities in the organization. This means that the performance of the employees poses as an important compound in achieving organizational goals. Hence, performance appraisal becomes a critical tool in motivating employees to be more productive and to ensure that the employees' outputs are aligned with the organizational objectives (Gichuhi et al., 2013). A critical evaluation on the outcome of performance appraisal may disclose the need for rewards, training, development and counseling among employees.

Healthcare providers today will have to deal with several challenges especially those in private sector which receive mostly foreign clients will need to overcome social, cultural and financial challenges (Taqdees, Shahab \& Asma, 2018). The impact from this is that patients are demanding for greater accessibility to higher quality of healthcare. Thus, it is significant for private hospitals to sharpen their competitive edge in order gain competitive advantage among other competitors. Consequently, the services and cares provided by healthcare employees are marked significant as a source of quality which can satisfy patients' demands. In view of this, performance appraisal act as an essential platform to notify healthcare employees the required standard of quality which able to meet patients' demands and eventually help private hospitals to achieve objectives.

With the Federal Government focussing on healthcare as an economic growth engine, Selangor state is very well placed to take advantage of a rapidly changing, competitive landscape. This landscape places a premium on the delivery of health services based on value, volume of its patients, procedures and reimbursements, and at the same time, responding to tensions and disruptions between key sub-sectors in the healthcare industry. These sub-sectors include pharmaceuticals, medical devices, biomedical, medical health insurance, research and teaching, health informatics and administration, food processing, nutraceutical and cosmeceuticals. 
Performance appraisal is an essential tool which being used widely in all organizations especially in hospitals which owned massive amount of diversified workforces. However, not all performance appraisal is being carried out effectively in these organizations. The problem rises with is that performance appraisal is degraded as it was said that it has been performed as a top-down and complex system owned by HR department rather than by the managers. The problems of this research is that what are the factors that can affect the effectiveness of performance appraisal in private hospitals and which of these factors generate greater impact in degrading the effectiveness of performance appraisal.

In view of the fast-changing environment in today's world especially in healthcare system, performance appraisal is said to be a tool to synchronize employees' performance with current newly invented medical technologies, increased patients' demands and fast-growing number of hospitals in Malaysia. Performance appraisal is playing an important role in all established organizations especially in hospitals where services are the primary source to attain return of profits. Indeed, the private healthcare industry in Malaysia is highly competitive, especially in the fastdeveloping state- Selangor. Many researchers also concerned on the effectiveness of performance in other highly competitive industry such as banking industry and automotive industry for healthcare institutions, performance appraisals can be particularly problematic (Bartz, 2017; Abbas, 2014).

Human resource managers are concerned about the performance of the employees in healthcare institutions when service the most significant output. The vast number of employees in healthcare institutions shows diverse work orientations, interests, and commitments, the effectiveness of performance appraisal is definitely low especially when the company adapt to a single tool to perform performance appraisal. There are many studies conducted on assessing the effectiveness of performance appraisal in Malaysia, however none of the study has concentrates on private hospital in Malaysia. Looking into the issue, factors that can affect the effectiveness of performance appraisal should be examined.

For this research, the authors focus on several factors that pose greater impact to the efficiency of performance appraisal conducted in the private hospitals in Malaysia. This study aims to achieve the objectives as follows:

1. To identify the effect of performance appraisal process, level of trust, perceived fairness and level of communication implemented towards the effectiveness of performance appraisal in private hospitals in Malaysia.

2. To suggest some solutions or strategies can be implemented in order to overcome the loophole that present in the performance appraisal system in private hospitals in Malaysia.

\section{LITERATURE REVIEW}

This section reviews on the key variables for this study, namely performance appraisal, performance appraisal process, level of trust, perceived fairness and level of communication. 


\subsection{Performance Appraisal}

Performance appraisal often functioned as a platform for managers to convey feedbacks on employees' performances and provide guidance or plan for them to achieve the targeted standards, which eventually reflects the success of execution of performance management. Stone (1995) defined performance appraisal as a measure of organizational effectiveness. McShane and Von Glinow (2015) further explained that level of efforts, commitment and the amount of creativity that an employee contributed to his or her jobs in an organization influenced productivity and these items were also included for their performance appraisal. This indicates that efforts devoted from individual employees are significant in ensuring that the organization goals are met. Managers played an important role by continually assessing their employees and evaluating them. Moreover, the evaluation process often serves as a merit or demerit point to determine employee salary increases, promotions, terminations, training opportunities and career development.

Common outcomes of implementing an effective performance appraisal are employees' selfimprovement on deficient areas and employees' knowledge about their progress. According to Mondy and Martocchio (2016), there are five outcomes from effective performance appraisal, i.e. acknowledged evaluations as positive feedback to improve performance, reduced turnover rate, increased employees motivation, increased feelings of equity among employees, and justifiable linkage between performance and rewards. Perlmutter and Bailey (2001) viewed provision of information for the development of managerial strategies for training and development as an outcome. Studies also found outcomes like reduced employee stress, review of overall progress, linkage between current performance and employee's goals, and development of specific action plans for future. Idowu (2017) founds that efficient performance appraisal system such as implementing appropriate appraisal tool and providing appropriate rewards have positive significant effect in motivating employees and increase employee satisfaction. In relate to this, expectancy theory stated that employees' performance is highly related to the outcome of performance appraisal. Expectancy theory often refers to the belief that one's tendency of being rewarded is highly influenced by his or her performance in the organization (Hiriyappa, 2015).

\subsection{Performance Appraisal Process}

According to Deb (2008), the appraisal process that practiced by all organizations are distinctive due to organizational culture and highly competitive environment. By employing a good performance appraisal process, the organization can evaluate the employees' outcomes much better. Recent studies also found that formal performance appraisal are crucial to measure employees' productivities (Curzi, Fabbri, Scapolan \& Boscola, 2019; Tweedie, Wild, Rhodes \& Bennie, 2019). Figure 1 shows that the steps that should be embedded in an ideal performance appraisal process. 
Figure 1: Performance Appraisal Process

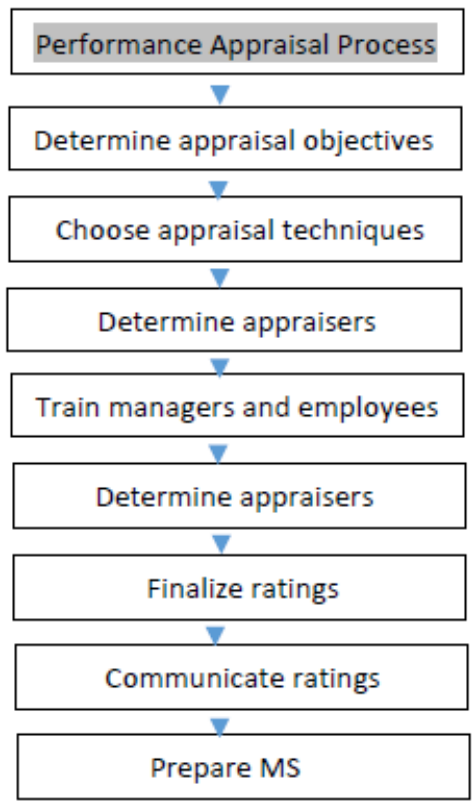

Source: Deb (2008)

Refer to Figure 1, performance appraisal process can be divided into planning, controlling and decision making. In the planning stage, the team will be involved in setting objectives that can meet organizational goals. Choosing an appropriate appraisal tool is significant in the planning stage as the appraisal tool shall merge to the size and culture of the organization, especially in a diversified workplace like hospital settings, departmental functions are crucial factor in determining the appropriate appraisal tool.

In controlling stage, training provided to managers and employees prior to the performance appraisal session is important, in order to minimize tendency of mistakes and obtaining the best results from the performance appraisals. It was reported that attitudes about the performance appraisal system and person in charges' competencies on the systems determined the tendencies of giving higher versus lower rating and the accuracy of the ratings (Ellen \& Amani, 2018; Deb, 2008). Trained appraisers are able to make comparison of employees' current performance against established standards in order to ensure that their performances are aligned with organizational objectives. Furthermore, forms relevant to performance appraisal system are distributed to managers to record the comments or remarks in the process of performance evaluation. With this, all necessary information and feedbacks are recorded and will be reviewed at the company level (i.e. HR level) to ensure that the comments are not biased and to ensure that the sounds of appraises are taken into consideration. For instance, severely negative feedback is depleting the confidence of employees towards performance appraisal system and eventually reduces its effectiveness (Curzi et al, 2019; Deb, 2008). The final appraisal results are discussed with employees and are given chance to question any misinterpretation during the performance appraisal session. 
Decision making is the choice of an outcome from among the alternative outcomes that were given to the decision maker (Fredie, Mbabazize \& Shukla, 2015). In performance appraisal system, decision making is crucial to determine outcomes of the performance appraisal such as promotion or demotion. All appraisal forms are consolidates in a systematic system (i.e. Management Information System) in order to allow the higher management to implement HR decision. The results are then analyzed to ensure fairness and justice is embedded in the whole appraisal process. The top management then decides on the rewards, promotion or compensation to be given to the employees. The following hypothesis was drawn based on the literature review.

\section{$\boldsymbol{H}_{1:}$ Performance appraisal process has positive effect on effectiveness of performance appraisal.}

\subsection{Level of Trust}

Performance appraisal accuracy often refers to accurate and trustable ratings which aim to avoid rating errors and biases. In the research done by Iqbal, Akbar and Budhwar (2015), found that there is a positive relationship between outcome of performance appraisal and level of trust between appraiser and appraisee. Level of trust of employee toward rates is essential component in determining effectiveness of performance appraisal (Brown, Gray, Mchardy, \& Taylor, 2015). However, level of trust is mostly affected by the sense of subjectivity that embedded within the appraiser or respondent, where every human judgement is subjective no matter how objective the situation is (Low \& Embi. 2012). Relationship and level of trust between employees and supervisors were found to have positive relationship towards performance appraisal in multinational corporations and influenced organizations' short-term profits (Maley \& Moeller, 2014). Recent research also stated that employees who trusted their appraisers revealed more information to their superiors and level of trust among employees and appraisers was among the factors that had impact on performance appraisal (Brown, O’Kane, Mazumdar \& McCracken, 2018; Boon, Hartog \& Lepak, 2019). The following hypothesis was put forwards.

\section{$\boldsymbol{H}_{2:}$ Level of trust has positive effect on effectiveness of performance appraisal.}

\subsection{Perceived Fairness of Performance Appraisal}

Organizational justice is referred to employees' perception on organizational processes and decisions and how these outcomes can influence their behaviors at work. Organizational justice is often relate closely to perceived fairness (Karam, et. al., 2019; Greenberg, 2004; Greenberg, 1997). Sudin (2011) stated that perceived fairness or organizational justice is crucial in performance appraisal process as it poses a huge impact on the effectiveness of performance appraisal where employees' job satisfaction, motivation and organizational commitment are highly affected. This can be related to equity theory which stated that the perception of fairness is determined by the amount of efforts committed compared to the rewards or compensation they received (Kollmann, Stockmann, Kenbock, \& Peschi, 2019; Peyton, 1994). For instance, employees will try to work on performance on low ratings only if they perceive the performance appraisal process was fair.

Fairness is made up of three types of subjective perceptions which included distributive justice, procedural justice and interactional justice (Sudin, 2011). Distributive justice is perceived fairness 
of distributed rewards or resources (Hess \& Ambrose, 2014). Here, perception of fairness of distribution will affect the behavior of the employee (Karam et al., 2019). For example, employees who received low salary increment will perceive this as unfair treatment and react negatively. Meanwhile, procedural justice is the perceived fairness employees had on the performance appraisal process which used to determine the outcome they received (Hess \& Ambrose, 2014). Interactional justice is perceived degree to which one is treated with respect (Inoue, Tsutsumi, Eguchi, \& Kawakami, 2019). Among the three forms of justice, distributive justice is highly related to employees' satisfaction with outcomes (i.e. get promoted) and organizational commitment, as they perceived fairness when they think that they received outcomes that they deserved. On the other hand, procedural justice is highly linked to job satisfaction, level of trust, turnover rate and task performance as employees will put efforts to achieve the desired outcomes and were given explanation of why they received the given rates (Inoue et al., 2019). Employees' perceived fairness has a direct impact on the effectiveness of performance appraisal that led to fair perception on performance appraisal system and eventually induces a positive impact on employees' performance in the organization (Zohaib, 2014). The satisfied employees will lead to increase in sense of organizational commitment which results in competitive organization performance (Karimi, Malik \& Hussain, 2011). $\mathrm{H}_{3}$ was postulated as follows.

\section{$\boldsymbol{H}_{3:}$ Fairness has positive effect on effectiveness of performance appraisal.}

\subsection{Level of Communication}

Communication refers to the process by which information is conveyed and fully apprehend between two or more parties (McShane \& Von Glinow, 2015). Effective communication is essential in an organization as employees work interdependently to support the daily operations. Indeed, communication is essential in conveying feedback in the event of conducting performance appraisal. An effective communication is in which it can transmit meaningful messages that encourages mutual understanding among the parties who involved in the process (Mishra, 2013). The first Communication Process Model by Shannon (1948) has laid the foundation for the later research in this area. The Communication Process Model is able to illustrate the key interpersonal characteristics of effective communication:

Figure 2: Shannon's (1948) Model of Communication Process

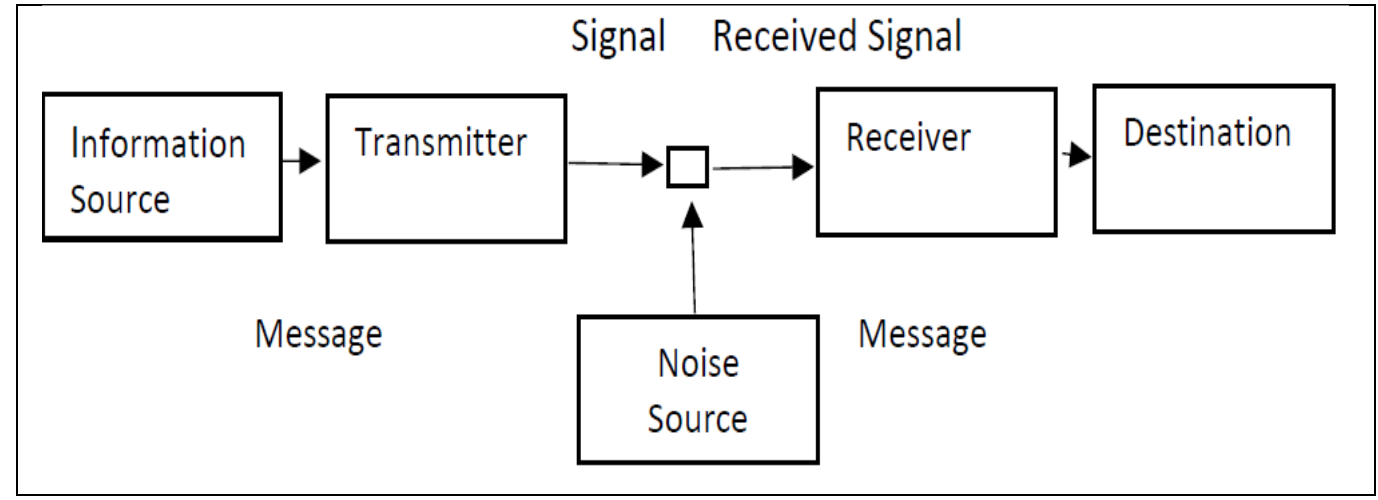

Source: Foulger (2004); Dowling (2013) 
The model explained that communications transmitted through channels between sender and receiver where encoding and decoding of message will take place, and meaningful message will be interpreted if the communication process is effective (McShane \& Von Glinow, 2015). Communication in term of performance appraisal is a segment of performance appraisal process of sharing and transmitting appraisals information from appraiser (i.e. encoding message) to appraises (i.e. decoding message) either through face-to-face discussion or through communication gadgets (Ismail, Kithuru Mohamed \& Rayee, 2016).

The context of employee evaluations takes on a somewhat different focus depending on whether one is appraising the performance of the kitchen staff, the nurses, medical technologists, the administration, or hospital volunteers. Communicating evaluation results to health institution employees can also be problematic because of the diversity of job scopes and responsibilities as well as their professional orientation and/or union affiliation. Therefore, this study hypothesizes that:

H4: Level of communication has positive effect on effectiveness of performance appraisal.

The research framework as follows:

Figure 3: Research framework

\section{Independent variables}

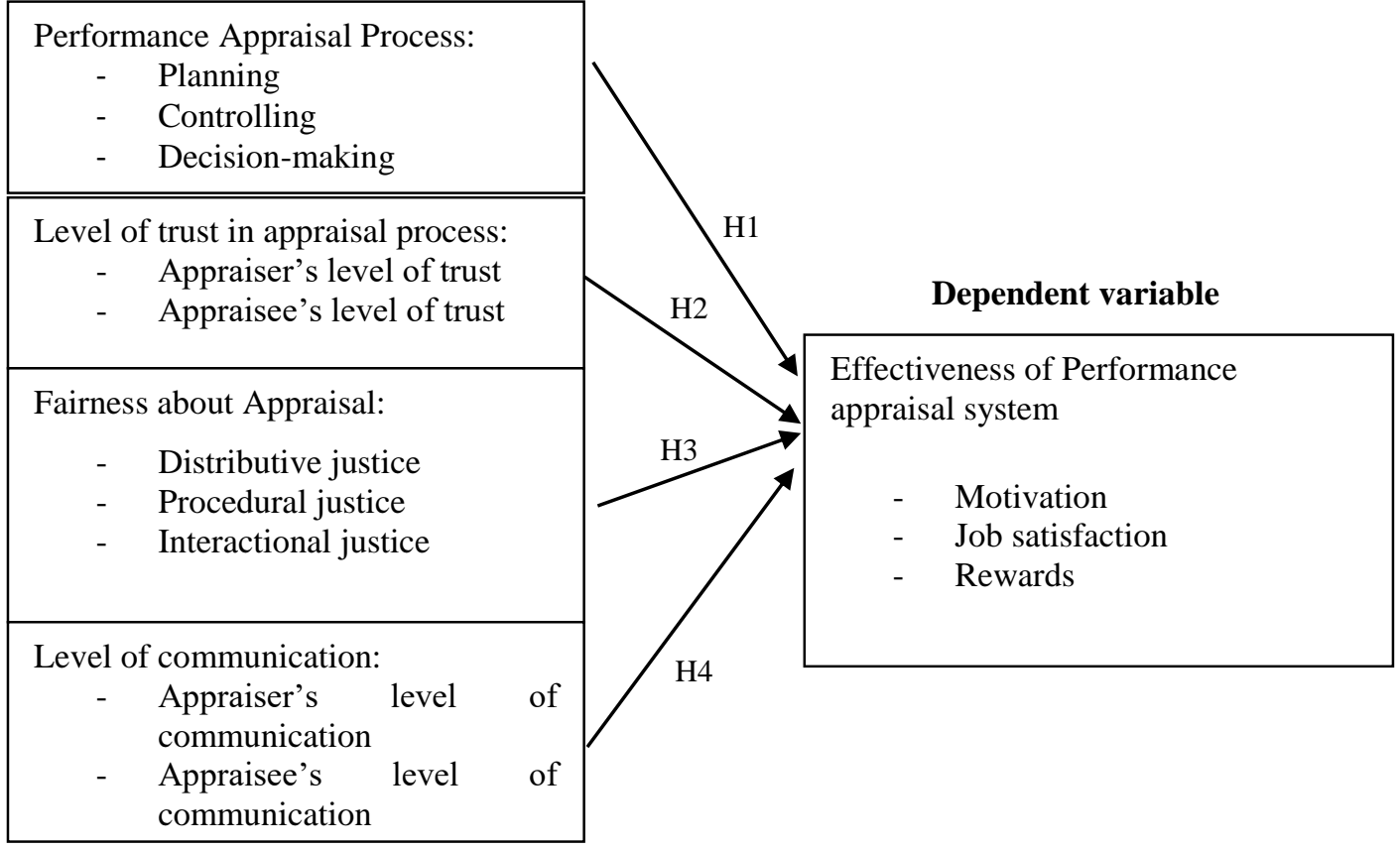




\section{METHODOLOGY}

The authors have obtained five sets of staff lists from five hospitals. The total population is 1000 . Prior to data collection, a pilot study was conducted with 10 respondents who were selected randomly from the selected private hospitals. A pretesting is also conducted initially in Jan 2018. The purpose of the pretesting is to determine the reliability of the instrument as well as to obtain some tentative evidence of validity. In view of the experience gained in the pretesting, questions may be modified and adjusted. These respondents were requested to give comments on the questions and if they have any doubts when they read the questions. The respondents were invited to attend a personal discussion session with the authors to further refine the questionnaires based on the Malaysian context. The insightful discussions were recorded, and some words used for the questions and sentences structure were adjusted for the questionnaires. 500 respondents were selected using simple random sampling technique for survey purpose. Research questionnaire were distributed by hand and email to the respondents and followed up by phone calls, text messages and face to face to collect the questionnaire. The authors managed to collect 200 sets questionnaires back. After screening the returned questionnaires, only 184 sets questionnaire are useable for data analysis.

The questionnaire used to tap responses consist of 32 items in all in which six items are about demographic information of the respondents, twenty items enquired about independent variables, five items about dependent variable and one item for opinion feedback. The source for the instruments used were adopted from different research studies for which the references were provided in the Table 1.

Table 1: References for the questionnaire

\begin{tabular}{lccc}
\hline \hline $\begin{array}{l}\text { Performance appraisal } \\
\text { process }\end{array}$ & References & Fairness & References \\
\hline $\begin{array}{l}\text { The employee appraisal } \\
\text { process provides a broad } \\
\text { range of information about } \\
\text { different areas of the }\end{array}$ & $\begin{array}{c}\text { Cravens et al. } \\
(2015)\end{array}$ & $\begin{array}{c}\text { I am able to express my } \\
\text { views and feelings } \\
\text { during the appraisal }\end{array}$ & $\begin{array}{c}\text { Harrington } \\
(2015)\end{array}$ \\
$\begin{array}{l}\text { The employee appraisal } \\
\text { process is fully } \\
\text { documented }\end{array}$ & $\begin{array}{c}\text { Cravens et al. } \\
(2015)\end{array}$ & $\begin{array}{c}\text { I think the appraisal } \\
\text { methods are consistent }\end{array}$ & $\begin{array}{c}\text { Harrington } \\
(2015)\end{array}$ \\
$\begin{array}{l}\text { The employee appraisal } \\
\text { process provides } \\
\text { information showing how } \\
\text { current performance of the } \\
\text { employee relates to the }\end{array}$ & $\begin{array}{c}\text { Cravens et al. } \\
(2015)\end{array}$ & $\begin{array}{c}\text { I feel that the appraisals } \\
\text { done are not biased }\end{array}$ & $\begin{array}{c}\text { Harrington } \\
(2015)\end{array}$ \\
$\begin{array}{l}\text { long-term goal of hospital. } \\
\text { The employee appraisal } \\
\text { process provides a range of } \\
\text { different types of } \\
\text { information that cover the }\end{array}$ & $\begin{array}{c}\text { Cravens et al. } \\
(2015)\end{array}$ & $\begin{array}{c}\text { The appraisal are done } \\
\text { based on accurate } \\
\text { information }\end{array}$ & $\begin{array}{c}\text { Harrington } \\
\text { (2015) }\end{array}$ \\
& & &
\end{tabular}




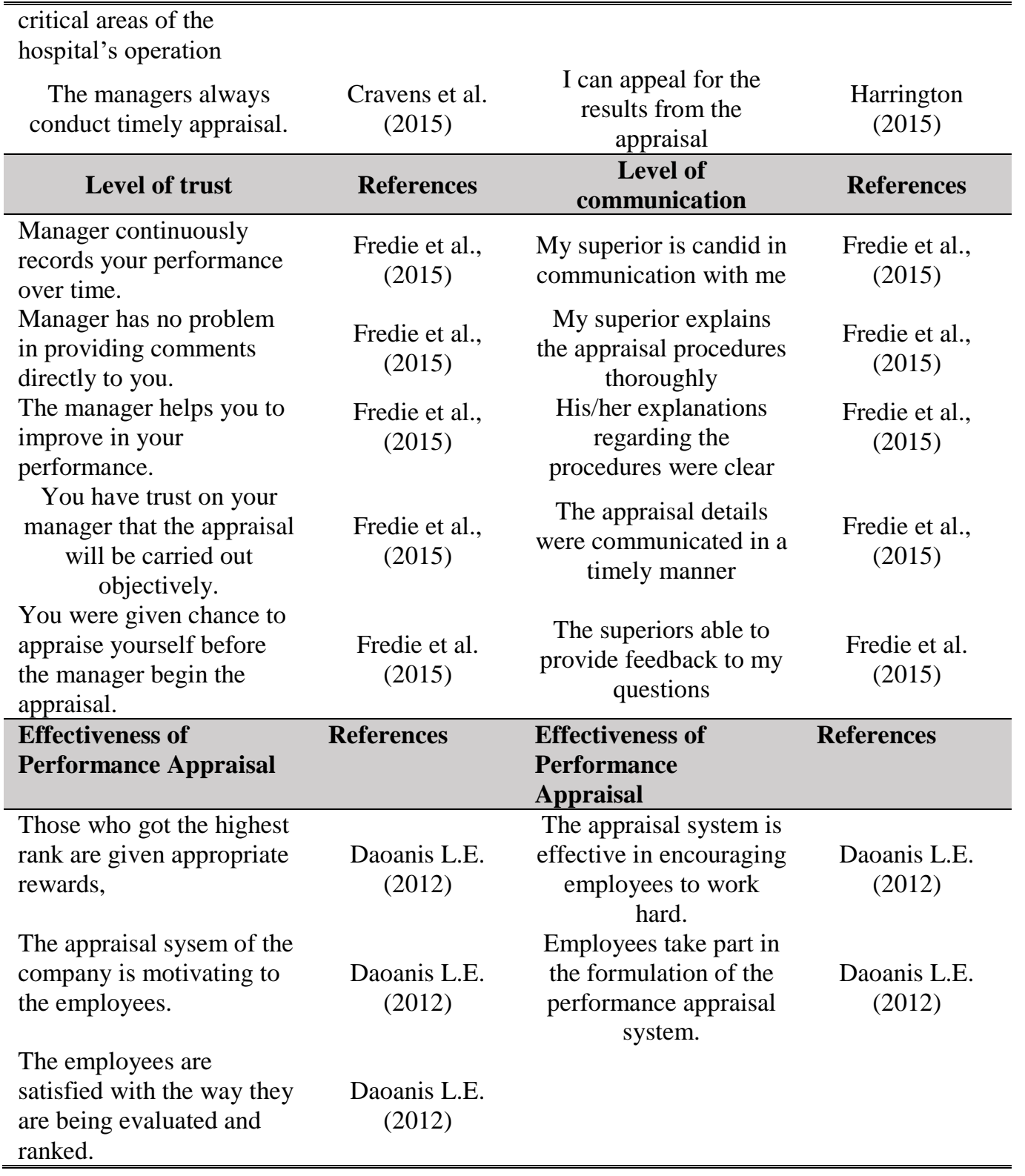

\section{RESULTS AND DISCUSSION}

The data collected is screened and analyzed through SPSS (Statistical Package for Social Science). Uniformity of data is examined by utilizing skewness, which conform to the required standards. Then, the parametric tests were used to analyze data and Pearson's correlation and linear regression 
analysis were carried out. For this study, all variables were checked for normality of distribution. The distribution was symmetric. The quantile-normal plot of the residuals confirms normality of errors. As shown in Figure 4 and Figure 5, the residual versus fit plot confirm linearity and equal variance. This indicates that the data has no normality and linearity problems and could be further analyzed.

Figure 4: Histogram and Normal Probability Plot

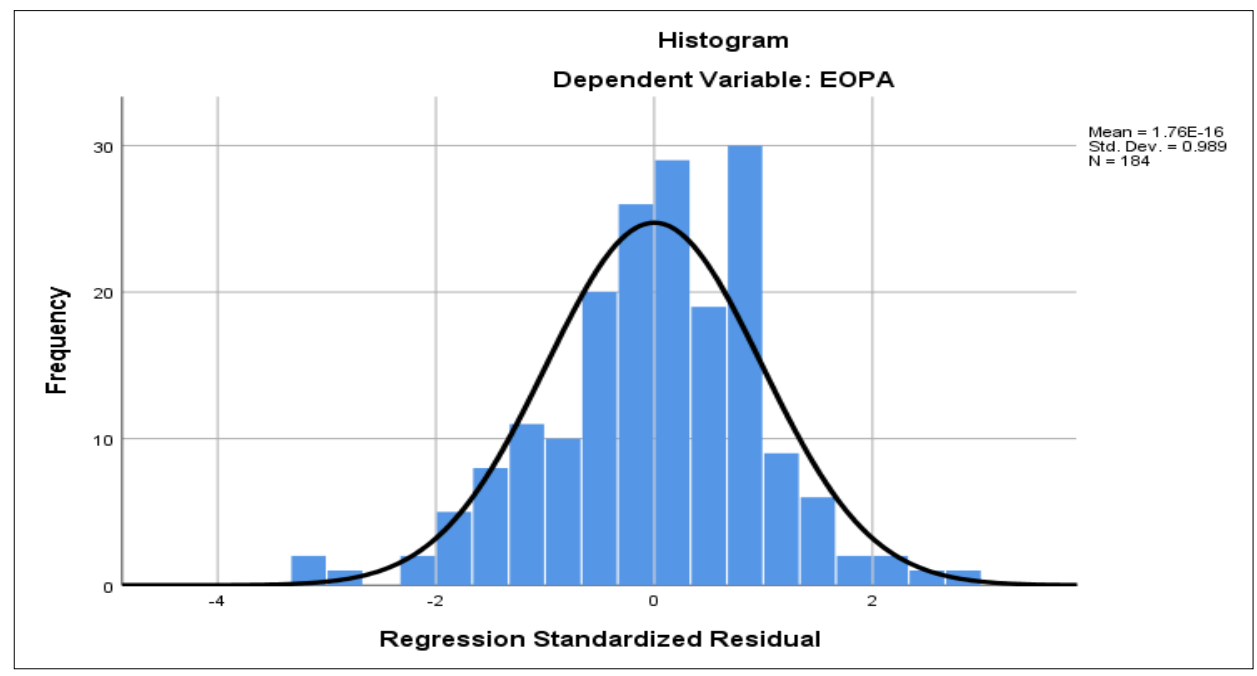

Figure 5: Normal P-P Plot

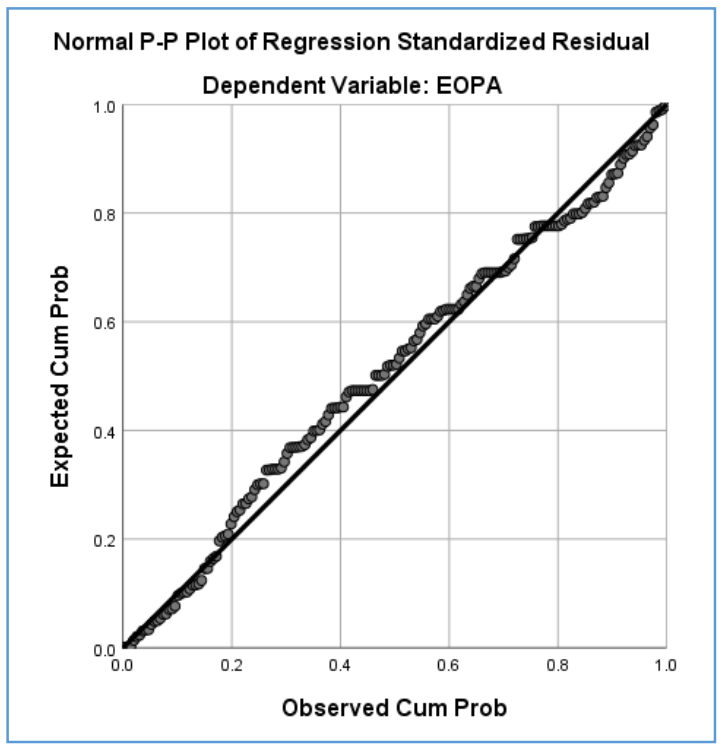


For the reliability test, all the variables show Cronbach's alpha values which are more than 0.7 , indicated that fair reliability (John, 2003; Adams, Khan, \& Raeside, 2014). Table 2 shows the reliability analysis of the variables presented in the study. A coefficient alpha ranged between 0.70 and 0.80 are interpreted as having good reliability while alpha value between 0.60 and 0.70 indicates fair reliability (John, 2003). Indeed, Hair, Black, Babin and Anderson (2010) stated that common lower limit for Cronbach's alpha is 0.70 . Thus, all the variables for this study are reliable as all recorded values are more than 0.70 .

Table 2: Result analysis results for variables

\begin{tabular}{lcc}
\hline \multicolumn{1}{c}{ Variables } & Number of items & Cronbach's alpha \\
\hline Performance appraisal process & 5 & 0.709 \\
Level of trust & 5 & 0.735 \\
Perceived fairness & 5 & 0.762 \\
Level of communication & 5 & 0.754 \\
Effectiveness of performance appraisal & 5 & 0.722 \\
\hline \hline
\end{tabular}

Correlations analysis was conducted to test relationship between independent and dependent variables. Table 3 shows these relationships. Pearson correlation is a bivarate analysis which is able to indicate several measures which included the linear relationship between two continuous variables, the strength of the linear relationship and the direction of the linear relationship (i.e. increasing or decreasing) (Schober, Christa, \& Lothar, 2018).

Table 3: Correlation matrix

\begin{tabular}{lccccc}
\hline \hline \multicolumn{5}{c}{ Correlations } \\
\hline & PAP & LOT & PF & LOC & EOPA \\
PAP & 1 & 0.179 & $0.287^{* *}$ & $0.175^{*}$ & $0.282^{* *}$ \\
LOT & $0.179^{*}$ & 1 & $0.169^{*}$ & $0.232^{* *}$ & $0.198^{* *}$ \\
PF & $0.287^{* *}$ & $0.169^{*}$ & 1 & $0.428^{* *}$ & $0.363^{* *}$ \\
LOC & $0.175^{*}$ & $0.232^{* *}$ & $0.428^{* *}$ & 1 & $0.242^{* *}$ \\
EOPA & $0.282^{* *}$ & $0.198^{* *}$ & $0.363^{* *}$ & $0.242^{* *}$ & 1 \\
\hline \hline
\end{tabular}

Notes: PAP: performance appraisal process; LOT: Level of trust; PF: Perceived fairness; LOC: Level of communication; EOPA: Effectiveness of performance appraisal

From the table 3 , the results had shown that performance appraisal process has a positive significant correlation of 0.282 with the effectiveness of performance appraisal at level 0.01. Likewise, for the other independent variables which included level of trust, perceived fairness, level of communication shows significant correlation at (0.198), (0.363), (0.242), at a level of 0.01 . The study shows that performance appraisal process has highest positive correlation relationship with perceived fairness at level 0.01 . Other variable shows positive significant relationship at level of 0.01 as well. 
Multiple regression analysis was conducted to examine the relationship between independent and dependent variables. Table 3 shows the findings of multiple regression analysis.

Table 4: Coefficient of multiple regression analysis

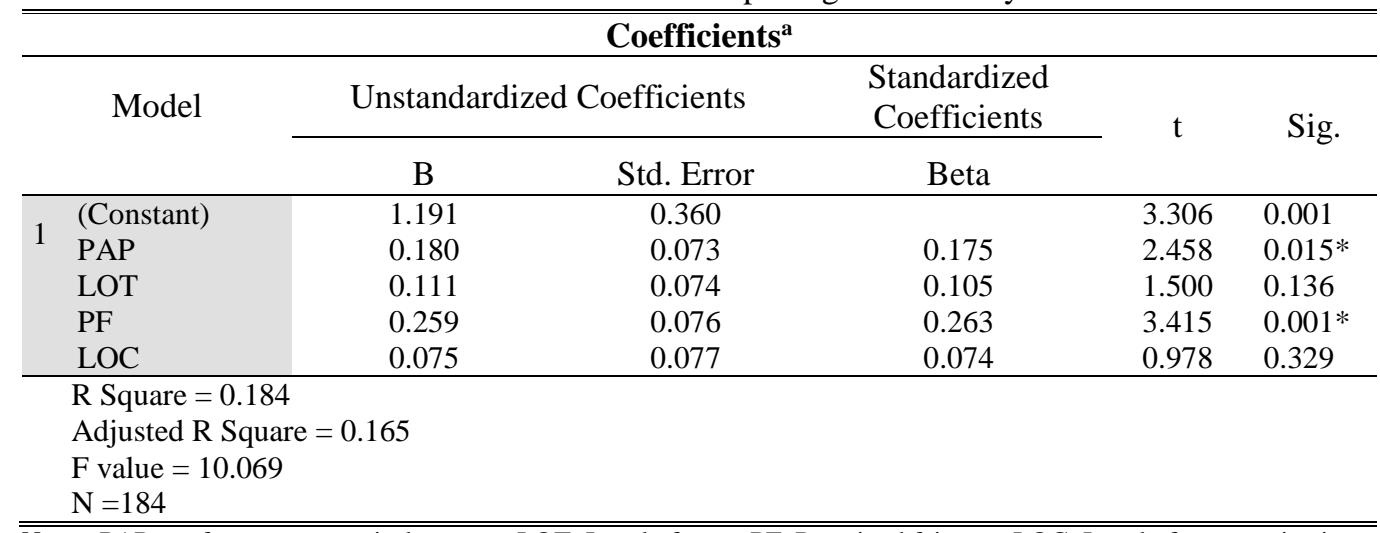

Notes: PAP: performance appraisal process; LOT: Level of trust; PF: Perceived fairness; LOC: Level of communication; EOPA: Effectiveness of performance appraisal

From regression analysis done, $\mathrm{R}^{2}$ value is significantly greater than 0 and this indicate that the predictors are able to account for a significant amount of variance in effectiveness of performance appraisal. Thus, the regression model is significant. From the ANOVA table (testing using alpha $=.05)$, the overall regression model was significant, $F(4,179)=10.07, \mathrm{p}<.001, \mathrm{R}^{2}=.184$.

From Table 4, the $\mathrm{p}$ value for each variable were analyzed, where $\mathrm{p}<0.05$ is considered as significant. Thus, from the results generated, it shows that there is a positive significant relationship between performance appraisal process and perceived fairness on the effectiveness of performance appraisal. This indicates that increase in overall performance appraisal process and perceived fairness of employees will increase the effectiveness of performance appraisal in private hospitals. Furthermore, the results also show that perceived fairness has the highest beta coefficient value (0.263), which means that it poses the greater impact on the effectiveness of performance appraisal.

The following section discusses about the results for hypotheses. Hypotheses 1 stated that performance appraisal process which included planning, controlling and decision making has a positive impact on the effectiveness of performance appraisal. From the above regression analysis shown in Table 2, there is a significant relationship between performance appraisal process and effectiveness of performance appraisal, where $\mathrm{p}=.015$ (sig. $\mathrm{p}<.05$ ). Thus, hypotheses 1 is accepted. This finding is supported by the previous study (Cynthia, 1985; Deb, 2008).

Hypotheses 2 stated that the level of trust has a positive impact on the effectiveness of performance appraisal. From the regression analysis in Table 2, the $\mathrm{p}$ value obtained for this variable is $\mathrm{p}=0.136$ which is more than .05 , result in the stated variable is not significant in affecting the effectiveness of performance appraisal. Thus, the hypothesis is rejected. The result is not concurrent with the 
previous study developed by Brown et al. (2015). As per stated that trust can be affected by subjectivity of the employee event given with positive rating (Low \& Embi, 2012).

Hypotheses 3 stated that there is a positive effect of perceived fairness on the dependent variable. Refer to the regression analysis in Table 2 , the $\mathrm{p}$ value of this factor is $\mathrm{p}=0.001$ which is considered as significant $(\mathrm{p}<0.05)$. The hypotheses is accepted. This means that increase of perceived fairness will increase the effectiveness of performance appraisal which supported by Ismail et al., (2016).

Hypotheses 4 assumed that there is a positive relationship between level of communication and effectiveness of performance appraisal. This hypothesis need to be rejected as the regression analysis shows that the $\mathrm{p}$ value is $\mathrm{p}=0.329$ which is more than 0.05 . There is no significant impact of level of communication towards the dependent variable. This does not support the earlier study by Bartz (2017) and Rondeau (1992).

Table 5 presents the summary for hypotheses results. As shown by the table, two hypotheses (H1 and $\mathrm{H} 3$ ) were accepted and the other two hypotheses ( $\mathrm{H} 2$ and $\mathrm{H} 4)$ were rejected.

Table 5: Hypothesis results

\begin{tabular}{clr}
\hline \hline H1 & $\begin{array}{l}\text { Performance appraisal process has positive effect on effectiveness } \\
\text { of performance appraisal. }\end{array}$ & Accepted \\
H2 & $\begin{array}{l}\text { Level of trust has positive effect on effectiveness of performance } \\
\text { appraisal. }\end{array}$ & Rejected \\
H3 & $\begin{array}{l}\text { Perceived fairness has positive effect on effectiveness of } \\
\text { performance appraisal. } \\
\text { Level of communication has positive effect on effectiveness of } \\
\text { performance appraisal. }\end{array}$ & Accepted \\
\hline \hline
\end{tabular}

In this study, four determinant factors which are extracted from previous studies were examined and tested. The generated results revealed that not all discussed factor has significant effect to the effectiveness of performance appraisal. Results show that performance appraisal process and perceived fairness are significant which able to positively affect the effectiveness of performance appraisal. However, results did show that level of trust and level of communication do not impact the effectiveness of performance appraisal in private hospitals in Malaysia.

From the results of significant studies mentioned above, hypothesis on the relationship between performance appraisal process and perceived fairness are accepted, while the hypothesis on the relationship of level of trust and level of communication are rejected. The deviate results from the previous studies are due to that most of the studies were done on banking and production industries instead of healthcare industry. Deviate results might cause by the difference of organizational cultural and practices.

Refer to the findings, it was noted that performance appraisal process is one of the significant factor in affecting effectiveness of performance appraisal. Thus, it is necessary for the human resource managers and regulators to analyze each stage of the performance appraisal process and make 
instant improvement and changes on the detected loopholes. Efficient performance process will well provision (i.e. controlling) is important to increase the confident of employees towards appraisal process.

\section{IMPLICATIONS OF STUDY}

From the theoretical perspective, this study helps to identify the effect of performance appraisal process, level of trust, perceived fairness and level of communication on the effectiveness of performance appraisal. Most of the studies which conducted previously only focus on an individual factor that can affect the effectiveness of performance appraisal, and none are conducted in the private healthcare industry. However, the past studies are able to devote as literature which examine the variables that involved in this study and constructed a theoretical framework as the basis of this study to examine the relationship between the variables. Indeed, this study also contributed to scholars by providing a new academic evidence for the private healthcare industry in Malaysia in regard to the factors that can affect the effectiveness of performance appraisal in the organizations of the mentioned industry.

In addition, this study helps managers to tackle on the significant factors which affect the effectiveness of performance appraisal instead of making wrong assumption and searching for wrong solutions. It is expected that the findings of this study can be utilized by management to formulate the organizational strategies to best fit with the human resource strategies (i.e. performance management). For instance, the results of the study show that performance appraisal process is one of the significant factors which impact the effectiveness of performance appraisal. Thus, management can focus on diagnose the problems lied within the process and also improve in the significant area. From the factor analysis conducted above, performance appraisal system which provides information related to long-term goals has the highest weightage. Thus, management should look into this during the planning phase in performance appraisal process, so that employees able to visualize and acknowledge expectations from their outputs in relate to organizational goals. In private hospital, one hundred percent customer satisfaction might be the informed measure in performance appraisal which congruent with the goal to achieve distinctive healthcare service provider.

These findings are also beneficial for policy maker in the organization in order to construct a more comprehensive policy that able to support the execution of effective performance appraisal system. As from the study, perceived fairness is also one of the significant factors which affect the effectiveness of performance appraisal, thus, the ratees should treated with respect and fairness. The interpersonal treatment provided is taken as a main contributor to the success of performance appraisal system. In order to ensure accuracy of the outcomes, the raters should eliminate subjective opinions and biasness during evaluation.

As mentioned earlier, outcomes of performance appraisal outcomes is highly related to the motivation and job satisfaction of employee, which can help to achieve organizational goals and reduce turnover rate. Thus, human resource management should improve the performance appraisal system by establishing an effectiveness-based system which emphasize on the 'objective' results which representing the employees' contribution to the job. This helps to improve the productivity of employees which is one of the important factors to achieve competitive advantage. 
Moreover, frequent constructive communication around performance adds value for the organization and employees. Performance feedback and appraisals can also be value added when correctly and fairly completed by managers and employees.

\section{CONCLUSION}

The healthcare industry relies greatly on the professional workforces in order execute its strategy and achieve objectives. Therefore, healthcare organizations especially private hospitals become increasingly concerned with the effectiveness of performance appraisal. In relate to this, the study carried out had examined the factors that can affect the effectiveness of performance appraisal in private hospitals in Malaysia theoretically and empirically. The study was conducted in five different private hospitals with the general employees as the main population. The results of the study indicates that performance appraisal process and perceived fairness served as the significant and key factor which affect the effectiveness of performance appraisal and should be focused by the human resource managers to improve on overall organizational objectives. However, according to the findings, level of trust and level of communication is not as significant to impact on the effectiveness of performance appraisal.

Furthermore, study carried out is able to answer the research questions and meet research objectives. Result from the study also able to provide implication to management to improve on performance appraisal efficiency and future suggestion for future research. The result of the study is beneficial for the organization to improve on the areas that can subside the productivity of employees and ultimately generate a better performance process and provision to increase the utility of performance appraisal system.

From the generated results, it is important that the performance appraisal systems should be outlined in such a way that the performance appraisal process is each stage of the process is embedded with implementations that are relevant to the practice of the employees from different departments. Besides, the layout of the performance appraisal system should create perceptions of fairness relative to employees' efforts and expectations. This can devote greatly towards positive attitudes, such as high motivation and greater effort in achieving organizational objectives.

Future studies can take into consideration to expand the area of study instead of concentrate in one particular state. Besides, researcher can utilize more research instruments instead of distributive survey to generate more data and to enrich the sources of data. For example, researcher can consider integrate both questionnaire and interview as the instrument for the study, so that more reliable data can be generated if two different instruments generating similar data.

Besides, researcher can incorporated more different types of analysis to test the significant and relationship between the variables. As can be seen, only four independent variables were included in the study, thus, more variables should be added to test the factors that can affect the effectiveness of performance appraisal. Performance appraisals are also an opportunity to reward and acknowledge employees for a job well done and for managers and employees to communicate openly about performance, allowing them to work together to develop goals and objectives for the upcoming yearin an ideal world. 


\section{REFERENCES}

Abbas, M. Z. (2014). Effectiveness of Performance Appraisal on Performance of Employees. IOSR Journal of Business and Management, 16(6), 173-178.

Adams, J., Khan, H., \& Raeside R. (2014). Research Methods for Business and Social Sciences Students ( $2^{\text {nd }}$ ed.). London: Sage Publications Ltd.

Armstrong, M. (2009). Armstrong's Handbook of Human Resource Management Practice. (1 1 th $^{\text {th }}$ ed.). Philadelphia: Kogan Page.

Bartz, D. E. (2017). Communication, Feedback, and Coaching Skills for Managers to Use with Staff Members During the Performance Appraisal Process. International Journal of Business and Social Sciences, 8(6), 34-46.

Boon, C., Hartog, D. N. D., \& Lepak, D. P. (2019). A Systematic Review of Human Resource Management Systems and Their Measurement. Journal of Management, 45(6), 24982537.

Brown, S., Gray, D., McHardy, J., \& Taylor, K. (2015). Employee Trust and Workplace Performance. Journal of Economic Behavior and Organization, 116, 361-378.

Brown, T. C., O'Kane, P., Mazumdar, B., \& McCracken, M. (2018). Performance Management: A Scoping Review of the Literature and an Agenda for Future Research. Human Resource Development Review, 18(1), 47-82.

Cappelli, P., \& Conyon, M. J. (2018). What Do Performance Appraisals Do? ILR Review, 71(1), $88-116$.

Curzi, Y., Fabbri, T., Scapolan, A.C., \& Boscolo, S. (2019). Performance Appraisal and Innovative Behavior in The Digital Era, Frontier in Psychology, 10, 1-2.

Cynthia, L. (1985). Increasing Performance Appraisal Effectiveness: Matching Task Types, Appraisal Process, and Rater Training. Academy of Management Review, 10(2), 322-331.

Deb, T. (2008). Performance Appraisal and Management: Concepts, Antecedents and Implications ( $1^{\text {st }}$ ed.). New Delhi: Excel.

DeNisi, A. S., \& Murphy, K. R. (2017). Performance Appraisal and Performance Management: 100 years of Progress? Journal of Applied Psychology, 102, 421-433.

Dowling, D. (2013, September 16-20). Enhancing Student Communication Skills: The Development of The PCR Communication Model for Engineers. Paper presented in $41^{\text {st }}$ SEFI Conference, Leuven, Belgium.

Ellen, V. R., \& Amani, E. (2018). The Performance of Performance Appraisal Systems: Understanding the Linkage Between Appraisal Structure and Appraisal Discrimination Complaints. The International Journal of Human Resource Management, 2018, 1-20. doi: 10.1080/09585192.2018.1424015.

Gichuhi, A. W., Abaja, P. O., \& Ochieng, I. (2013). Effect of Performance Appraisal on Employee Productivity: A Case Study of Supermarkets in Naruku Town, Kenya. Asian Journal of Business and Management Sciences, 2(11), 42-58.

Foulger, D. (2004). Models of Communication Process. Retrieved from: http://davis.foulger.info/papers/ecologicalModelOfCommunication.htm

Fredie, N., Mbabazize, M., \& Shukla, J. (2015). An Assesment of Factors Affecting the Implementation of the Performance Appraisal System in Rwanda: A case of 
Nyamasheeke District Local Government (NDLG). International Journal of Business and Management Review, 3(4), 1-35.

Greenberg, J. (1997). A Taxonomy of Organizational Justice Theories. Academy of Management Review, 12(1), 9-22.

Greenberg, J. (2004). Stress Fairness to Fair No Stress: Managing Workplace Stress by Promoting Organizational Justice. Organizational Dynamics, 33, 352-365.

Hair, J. F., Black, W. C., Babin, B. J. \& Anderson, R. E. (2010). Multivariate Data Analysis: A Global Perspective. New Jersey: Prentice-Hall.

Hess, R. L., \& Ambrose, M. (2014). The Four Factor Model of Justice: An Application to Customer Complaint Handling. The Differential Effects of Justice on Affective and Behavioral Responses (pp. 1-14). International Business and Economic Conference.

Hiriyappa, B. (2015) Management of Motivation and Its Theories. California: Createspace Independent Publishing Platform.

Idowu, A. O. (2017). Effectiveness of Performance Appraisal System and its Effect on Employee Motivation. Nile Journal of Business and Economics, 5, 15-39.

Inoue, A., Tsutsumi, A., Eguchi, H., \& Kawakami, N. (2019). Organizational Justice and Refraining from Seeking Medical Care Among Japanese Employees: A 1-Year Prospective Cohort Study. International Journal of Behavioral Medicine, 26(1),76-84.

Iqbal, M. Z., Akbar, S., \& Budhwar, P. (2015). Effectiveness of Performance Appraisal: An Integrated Framework. International Journal of Management Reviews, 17(4), 510-533.

Iqbal, M. Z., Akbar, S. Budwar, P., \& Ali, S. Z. (2019). Effectiveness of Performance Appraisal: Evidence on The Utilization Criteria. Journal of Business Research, 101, 285-299.

Ismail, A., Kithuru Mohamed, N. A., \& Rayee, M. R. (2016). Relationship between Performance Appraisal Communication, Procedural Justice and Job Satisfaction. Malaysian Journal of society and Space, 12(2), 15-26.

John, W. C. (2003). Research Design: Qualitative, Quantitative and Mixed Method Approaches ( $4^{\text {th }}$ Ed.). Newbury Park: International Educational and Professional Publisher.

Karam, E. P., Hu, J. Y., Davison, R. B., Juravich, M., Nahrgong, J. D., Humphrey, S. E., \& DeRue, D. S. (2019). Illuminating the 'Face' of Justice: A Meta-Analytic Examination of Leadership and Organizational Justice. Journal of Management Studies, 56(1), 134-171.

Karimi, R., Malik, M.I. \& Hussain, S. (2011). Examining the Relationship of Performance Appraisal System and Employee Satisfaction. International Journal of Business and Social Science, 2(22), 243-247.

Kollmann, T., Stockmann, C., Kenbock, J. M., \& Peschi, A. (2019). What Satisfies Younger versus Older Employees, and Why? An Aging Perspective on Equity Theory to Explain Interactive Effects of Employee Age, Monetary Rewards, and Task Contributions on Job Satisfaction. Human Resources Management, 59(1), 101-115. doi: https://doi.org/10.1002/hrm.21981

Low, K. C., \& Embi, M. A. (2012). Subjectivity, Organizational Justice and Performance Appraisal: Understanding the Concept of Subjectivity in Leading Towards Employees' Perception of Fairness in the Performance Appraisal. Social and Behavioral Sciences, 62(2012), 189193.

Maley, J. F., \& Moeller, M. (2014). Global Performance Management Systems: The Role of Trust as Perceived by Country Managers. Journal of Business Research, 67, 2803-2810. 
McShane, S. L., \& Von Glinow, M. A. (2015). Organizational Behavior: Emerging Knowledge, Global Reality. McGraw-Hill Education.

Ministry of Health Malaysia (2013). List of Hospitals in Selangor. Retrieved from: http://www.moh.gov.my/english.php/database_stores/view_store_search/3

Mishra, K. (2013). Exploring the Communication Centered Approach of Performance Appraisal. Amity Global Business Review, 8(1), 31-36.

Mondy, R. W., \& Martocchio J. J. (2016). Human Resource Management (14 ${ }^{\text {th }}$ Ed.). Harlow: Pearson Education Limited.

Perlmutter, F. D., Bailey, D., \& Netting, F. E. (2001). Managing Human Resources in the Human Services: Supervisory Challenge. New York: Oxford University Press.

Peyton, Y. H. (1994). Equity: In Theory and Practice. New Jersey: Princeton University Press.

Rondeau, K. V. (1992). Constructive Performance Appraisal Feedback for Healthcare Employees. Hospital Topics, 70(2), 45-58.

Schober, P., Christa, B., \& Lothar, S. (2018). Correlation Coefficients: Appropriate Use and Interpretation. Anesthesia \& Analgesia, 126(5), 1763-1768.

Shannon, C. E. (1948). A Mathematical Theory of Communication. The Bell System Technical Journal, 27, 379-423, 623-656.

Stone, R. J. (1995). Human Resource Management. ( $9^{\text {th }}$ ed.). Milton: John Wiley \& Sons Australia, Ltd.

Sudin, S. (2011). Fairness of and Satisfaction with Performance Appraisal Process. Journal of Global Management, Global Research Agency, 2(1), 66-83.

Taqdees, F., Shahab, A. M., \& Asma, S. (2018). Hospital Healthcare Service Quality, Patient Satisfaction and Loyalty: An Investigation in Context of Private Healthcare Systems. International Journal of Quality \& Reliability Management, 35(6), 1195-1214.

Tweedie, D., Wild, D., Rhodes, C., \& Bennie, M. N. (2019). How Does Performance Might Affect Workers? Beyond HRM and Its Critique. International Journal of Management Reviews, 21(1), 76-96. 